\title{
Domestic Violence Cases In Jambi: Psychological Factors That Affect Victims to Return Back to Their Offenders
}

\author{
Yurni $^{1}$ \\ ${ }^{1}$ Departement of English Education, Faculty of Teachers Training and Education, Universitas Batanghari, Jambi, Indonesia \\ Correspondence: Yurni, Departement of English Education, Faculty of Teachers Training and Education, Universitas Batanghari, \\ Slamet Riyadi Street, Jambi, Indonesia. Tel: 62-812-7262-1805. \\ Correspondence email: yurni@unbari.ac.id
}

\begin{abstract}
Most of the domestic violence cases proofed that woman was always be a victim in their own house. Economy will always be the first reason for offenders (husband) to do violence against their wife. Many cases happen but only a few women who have the brave to go to the court to have justice, others choose to keep silent. From these few women, some of them choose to return back to their husband after they see the judge and have sentence for their husband. This study tried to find out psychological factors that may affect women to have reconciliation with their husband. The author performed qualitative analysis on data from interview to four participants who have been consulted their cases on court and experienced domestic violence from their husband. Violence that they got vary from physical such as hitting, punching, and violence using tools (throwing plate or glass to the victim); psychology such as yelling, negative statement, neglected; economy such as not giving money to support their life. Data gained from interview showed that, some victims economically independent, its mean they have their own income but some are dependent; they still need support from their husband as the offender. Negative statement as they daily consumption have been internalized, it made them see their future helpless without husband; children become the other reason why victim choose to recon ciliate, they don't think they could support their children economically. Social stigma as a widow make them afraid to be separate from their husband. Victims experiencing domestic violence have low self-concept, low self-esteem and low selfimage. Those are become main factors that affect them to return back and have reconciliation with their husband. Having no goal setting and direction in their life become minor factors.
\end{abstract}

Keywords: psychological factors; domestic violence

\section{INTRODUCTION}

In late five years, domestic violence in Indonesia raise significantly. It could be proofed every day in national Television aired violence happened in household. Domestic Violence just like an iceberg, why so? Cases that come up not the real data. Its real a surprise for Jambi, a small city in Indonesia, showed a significant escalation in these four years. Data gained from P2TP2A (center for woman and child protection) Jambi showed an increase violence for woman and child year by year (table.1 and 2). Johnson (2005) stated that domestic violence is not merely about gender. He points out that domestic violence not only about taking out control over one's partner but also violence that response to intimate terrorism. Its mean that man and woman can be the actors of violence. On the other hands data from Independent volunteer networks (JaRl) period April 2002 to June 2007, showed that $92 \%$ of 263 domestic violence cases, woman are the victims.

Jambi is a province located in Sumatera Island of Indonesia. Population are come from many different culture, such as Javaness, Batakness, Padangness, Sulawesiness, Chiness etc but the original population is Melayuness. Each of the culture belong to matrilineal or patrilineal, mix marriage between culture happens a lot, because in daily life they live side by side. According to P2TP2A Jambi, based on the data of victims visit the center indicated that there is a relationship between culture and domestic violence case. Husband come from patriarchy culture tend to be an actors of violence.

Domestic violence can involve a wide array of physical, sexual and emotional. Until recently, in most part of the world, a husband a legal right to his wife's body. Domestic abuse is the leading cause of injury to women even in the world's most developed country. Many factors that contribute to domestic violence to woman, one is alcohol (Stanley, 2012). Women who are dependent on their partner may be more tolerant of spousal abuse (Yount and Carrera, 2006) man with fewer resource than his partner may bolster his dominance with force. Women psychological dependence has been positively associated with minor physical violence and women's economic dependence has been positively associated with severe physical violence (Kalmuss and Straus, 1982). Beside economic dependency, emotional dependency also contribute to domestic partner abuse in family (Bornstein, 2006)

Domestic Violence refers to assaultive and coercive behaviors that adults use against their intimate partner and surveys show that domestic violence against women is widespread. Indonesia Laws no 23 years 2004 stated that violence in domestic area are any action to a person especially to a woman, that could affected her sorrow or injuries physically, sexually, psychologically and/or abandon (Laws, 2004)

Table 1. Data of Domestic Violence in Jambi year 2010 and 2011

\begin{tabular}{|c|c|c|c|c|c|c|c|}
\hline \multirow[t]{2}{*}{ Year : 2010} & \multicolumn{2}{|r|}{ Total } & & \multirow[t]{2}{*}{ Year 2011} & \multicolumn{3}{|c|}{ Total } \\
\hline & Child & Woman & Man & & Child & Woman & Man \\
\hline Abandon & 3 & 10 & - & Abandon & 2 & 20 & - \\
\hline Psychology & 13 & 20 & - & Psychology & 2 & 25 & - \\
\hline Physics & 5 & 11 & - & Physics & 2 & 16 & - \\
\hline Sexual & 9 & 5 & - & Sexual & 13 & 2 & - \\
\hline
\end{tabular}




\section{Woman Client Case status}

Resignation

In Law process
Woman Client Case status

Resignation

In Law process
Exposure to violence can increase risks of major depression and suicidal ideation (Ferguson, et all. 2005) as well as injuries, fear, post-traumatic stress disorder, suicide and homicide. Psychological effects may cause by domestic violence. People who experience violence by years may change how they see them selves, by other words they may decrease in self-concept. Selfconcept is the individual's beliefs about himself or herself, including person's attributes and who and the self is (Baumeister, 1998).the self- concept includes many things that might not be part of one's identity. Selfesteem and self-image are an important part of selfconcept. A self concept is not merely an abstract summary or nation of the self but it is full of evaluation, that is, of perception of the self as good, bad or mediocre.
Self esteem is related to frequency and severity of physical and/or psychological abuse (Lynch and Graham-Brmann, 2004). Another statement come from Papadakaki et all (2009) stated that low self- esteem can weaken a woman's tie to her community and therefore cause an even larger detriment in her confidence and ability to change her situation. Research by Itzhaky and Porat (2005) on battered women proofed that women who leave their abusive partners are usually overwhelmed by feeling a lack of social support and failure to recognize their own abilities. This eventually leads the women to return to the abusive environment for emotional or financial security (Itshaky and Porat, 2005).

Table 2. Data of Domestic Violence in Jambi Year 2012 and 2013

\begin{tabular}{|c|c|c|c|c|c|c|c|}
\hline \multirow[t]{2}{*}{ Year : 2012} & \multicolumn{3}{|c|}{ Total } & \multirow[t]{2}{*}{ Year 2013} & \multicolumn{3}{|c|}{ Total } \\
\hline & Child & Woman & Man & & Child & Woman & Man \\
\hline Abandon & 2 & 20 & - & Abandon & 2 & 10 & - \\
\hline Psychology & 2 & 26 & - & Psychology & 18 & 30 & - \\
\hline Physics & 2 & 16 & - & Physics & 7 & 16 & - \\
\hline Sexual & 13 & 2 & - & Sexual & 7 & 7 & - \\
\hline Woman & & & & Woman & & & \\
\hline Resignation & & 2 & & Resignation & & 1 & \\
\hline In Law process & & 2 & & In Law process & & - & \\
\hline
\end{tabular}

Source: P2TPA Jambi Province

\section{METHODS}

The qualitative data come from semi structured, in-depth interviews with four women who experienced domestic violence from their spouse. Participant were clients who come to center for women and child protection in Jambi Province, during year in 2013. They, initially come to report their partner abuse and want a justice and protection from law. They come by their own motivation.

The criteria for selecting the participant limited only to four women, because they willing to come to judge for their case but finally they decided to come back to their spouse after the decision of the judge. Their case was handled in year 2013. Each of the participant have an interview season, they were scheduled to come to the center twice a week in minimum during one month.

\section{Measures and data analysis.}

From total number of 30 cases of victims that reported to the Center, we took only four case for some reason in spite of our criteria above. Not all victims want to share their case openly; they come to the Center because their family asked them. Their data were recorded, they were asked to answers some question concerning their case. After several sessions of interview they were asked to fill Sorensen scale of self-esteem (2006) consist of 50 statement about their self. Score one was given for the right answer and score zero for the wrong answer, sum total indicated the self esteem of the respondent.

The researcher used WHO guidelines and adapted question from the WHO Violence Against
Women Instrument (WHO,2003). This instrument consists of two sets of questions designed to capture information critical to assessing the prevalence, frequency and severity of different forms of violence against women, perpetrated both by intimate partners and others. The first set of question focuses on violence perpetrated against women by their intimate partners (questions 703 to 706, 709, 801, 802, 904 and 905 in the core questionnaire). These question on partner violence explore aspects of controlling behaviors, emotional abuse, physical violence, and sexual violence (703-706) as well as physical violence during pregnancy (709). This section also has question for women who have suffered physical violence by an intimate partner, that assess the degree of injury (801) and 802. Finally there are two question that explore whether the woman herself used violence against her self, and whether this aggression was offensive or in self-defense (904 and 905). The instrument does not aim to document every abusive action that a woman may experience, but rather aims to assess whether the respondent is likely to be experiencing 'severe' and/or 'moderate' level of abusive in her relationship. The question on injury contribute to providing a crude measure of severity of the violence. They should not be interpreted as a measure of the health effect of violence.

\section{RESULT AND DISCUSSION Qualitative findings}


Table.3 Data of the Participant

\begin{tabular}{llrlllll}
\hline No & $\begin{array}{l}\text { Name of } \\
\text { respondent }\end{array}$ & Wife & $\begin{array}{c}\text { Age } \\
\text { Husband }\end{array}$ & Wife & $\begin{array}{c}\text { Job } \\
\text { Husband }\end{array}$ & Kind of Violence & Husband \\
Origin
\end{tabular}

Kind of physical violence that participant got were: yelling, body blow and a slap. Mrs.N (44 yrs) provided an explanation: "....its seem body blow is my daily consumption. I don't know how much bruise I have since the first time he hit me. He start to abuse me physically since ten years ago, when his business got bankrupt. Before, he is a business man, he has car rental and have many clients, but one of his partners cheat him and made him bankrupt. He then, drunk and use alcohol, come home late at night. If anything at home didn't match to his taste, then he will yell at and throwing plates or things."

Another explanation from Mrs.E (20 yrs) about physical violence that she got:".....my husband beat me for no reason. He treat me like I am a target of boxing. Unfortunately he do it when we were alone, no one of my child saw it. My family think that he is a nice man, a good husband...o yeah because he never show his temper in front of them. For the first moment when some one see my husband he is a kind of gentleman but in my room he is not. He could slap me until I got bruise at all my body, but he left my face look smooth, not bruise at all there. Another time he treats me like a princess, he gave me all that I want. He provided me with much money. Some time I think my husband is sick."

The same physical violence happen to Mrs.S (35 yrs), a Vet. She said:"...... marry my husband when we were younger, I was 20 and he was 25 , we struggled to have my parent permition at that time. I was a student at Vet school and he was a fresh graduate from a university. He worked very hard to support my study at university until I got my vet. It was so sweet....but lately he become a rough man, he kicked me, slap over me and treats me with any things he could reach: plate, glass, vase etc. I tried to understand my husband, but I couldn't stand it anymore. My body was tired."

All the participant got psychological violence, such as negative statement and verbal abuse. Mrs. T (35 yrs) a teacher at secondary school. Her husband is a police. They have two teenage daughters. Her husband's verbal abuse make Mrs. $\mathrm{T}$ become emotionally down and have lower self image. She said:"...... it seems to me that, all my husband did to me were right. He said that I am not a pretty wife, I am an old style, I am stupid being a teacher is only my fortune not because of my competence. I know that he never love me since we married, this was an arranged married. Our parent were best friend and colleague. Another experience of psychological violence from Mrs. E (20 yrs) explained that:".............my husband convince me that I am a weak woman, I have no source, economically I depend on him. My live without him was nothing. His words internalize in my memory, he said it always and always. I know he is a rich man from prestigious family, he support me economically to buy luxurious things. I am only a high school graduate with two little son, what can I do without him. His negative words is getting my routine breakfast, some time he got enough. Some time I feel I must showed him I am not just as he think I am, I want to fight but I never have my brave."

Intimidate and humiliation was another example of psychological violence. Comment provided by Mrs. S (35 yrs):"......my husband intimidate me, he said he own my life and my success is because of him. If I did anything to betrayal him he will take my kids away from me. Sometime he humiliate me in front of his big family, he said that I am a bad example of wife, that I could not take care of him very well. Things that embarrassed me when he humiliate me in front of my neighbor. I can accept all of this unless he humiliate me in front of my kid."

Sexual violence experienced by Mrs. E (20 yrs) and Mrs. T (35 Yrs). Interview with Mrs. E (20 yrs) explained that she got sexual violence during intercourse with her husband. Mrs E said:"....i always feel worry anytime when my husband ask me to have sexual intercourse. He sometimes use things and I always get injured." At another interview session Mrs. E said she sometime enjoy her sex with husband:"....there was a time when he treat me softly, like a woman. Kissing me and touching normally. But I cannot predict when he will act like that. His emotion is a mysterious things, like two side of coin really different."

Mrs. T (35 yrs) explain about her sexual violence experience. She said:".........sex is a shame experience to me. Actually it is very hard to me to tell it, but I want some one to know and understand me. During years I kept my secret alone. My profession as a teacher make me think twice to open this case to public." Sexual violence that Mrs.T got from her husband made her selfconcept and self-image low (data from self-esteem scale showed that she got 30 point, its mean low self-esteem). Mrs.T said:".....i don't think that I am capable in controlling my live, I don't have much friends, because I don't know how to talk to others. My life only in my house." Low self-self esteem make Mrs T allowed her husband to do unusual thing during sexual interaction. She said:".......my husband desire to have sex is very big. He asked me to have sex anytime he want, sometime when I am in my period. Actually, there was a time when I am so tired, he asked me to have sex, he then hit me and punch me, because I gave him my bad face. He want me to smile when we were having sex."

Cultural origin and background give an impact to domestic violence (Crichton-hill,2001) . Bates et all (2004) believe that personal, situational and sociocultural factors influence domestic violence. Myth about domestic violence to be prejudicial stereotyped or plays a large role in perpetuating these myths that enables perpetrators of domestic violence and 
promote victim blaming (Stanley, 2012).Patriarchy is predicted to be one factors that could elicit domestic violence (Tracy, 2007). Mrs.N and Mrs.S, both have husband come from North Sumatra, that belong to patriarchal culture. Patriarchy is the prime obstacle to women's advancement and development (Sultana, 2010). Principle of patriarchy remain the same even though there is the difference in level of domination in each area, men are in control. Cases of Mrs.N and Mrs. $S$ showed their husband domination in family. They just accept all their husband violence to them during years because they think that is husband role. In patriarchy culture, people believe that men are superordinate and women are subordinate.

Alcohol and drugs could increase the probability of partner to do violence to their spouse (Stanley, 2012). Case for Mrs. N (35 yrs) indicated that her husband use alcohol. From interview Mrs. N said:".....my husband use alcohol. Anytime he got drunk, he hits me." Personality is another problem that could cause violence. Case of Mrs. E, showed that her husband has personality disorder. He could be nice and bad at the same time. Mrs.E said:"....some time I think he really love me but at the same time I think he treat me like an object."

Reason why victims didn't separate from their husband, indicate there is psychological factors such as low self-image, low self-esteem, low self-concept and social stigma. Low self-image indicate from Mrs. T. she said:".... i am not an ideal women, I am fat and not beautifull." From interview season, it could be concluded that her low self-image make her not sure to have a better live without her husband. Low self-concept indicate by Mrs.S, Mrs.N and Mrs.E, for a question "how do you explain your self in general?" their answer were:".... am no a success woman, I am fail to be a mother and a wife" (Mrs.S); while Mrs.N provided an answer:"....... am deserve to have this (violence), my husband is my leader in house. I have to try more to please him, that's my duty as a wife." The same comment come fro Mrs.E:".....he is (husband) the only man who want to marry me. My other boyfriends only give me promise not reality. I have so much luck to have him,even he rude to me but I think that he should do that as a leader of the family."

Economis factor and social made victim think twice to leave their husband. Wife dependent to their husband economically afraid to be a single parent, they don't know how to support their live without husband. Social stigma about being a widow made them afraid to have that status. Becoming a widow is a negative status in society, its mean that someone failed and useless. Some respondent showed no goal direction, they are not ready to live alone.

All participant has the same answer when researcher asked the question:"why you don't leave your husband, you know he treat you badly?" and their answer is: "love, I still love him, no matter what he did to I forgive him (Mrs.N). love become a mysterious thing to explain why victims still reconciliate to their offender, definition of love varies between respondents. Mrs $\mathrm{E}$ said:"....some time he is a good man, he show me his love by giving me anything I need and support my children." Mrs. S said:".....i need him and he need me, he ever said that he couldn't live without me. That's enough for me to reconciliate."

The conclusion is psychological factors such as low self-concept, low self-image and low self- esteem impact victims decision to reconciliate to her husband. Even they have come to the judge and their husband sentenced to be guilty, but at the end they say sorry and want to forgive their husband because of love that their translate. The victims realize about social stigma of being a widow, is negative and they were afraid of that. Economy dependency and child support as well as no goal direction made victims think twice to divorce. Suggestion derived from this research were life skill training for victims, psychological empowering to grow their potential self and positive self-concept.

\section{REFERENCE}

Arthur, Christine.,and Clark, Roger.2009. Determinant of domestic Violence: A cross national Study. International Journal of Sociology of the Family, vol.35. No.2

Bates,Lisa.,Sydney,Ruth., Islam, Farzana., and Islam, Khairul. 2004. Socioeconomic factors and processes associated with domestic violence in rural Bangladesh. International Family Planning Perspectives, Vol.30 no.4

Baumeister, R.F. 1993. The self. In D.T.Gilbert,S,T.Fiske, and G.Linzey (eds). Hand book of social psychology $\left(4^{\text {th }}\right.$ ed).New York: McGraw Hill

Bornstein, Robert F. 2006. The complex relationship between dependeny and domestic violence: converging psychological factors and social forces. American psychologist. Vol. 61 No.6

Crichton-Hill, Yvonne. 2001. Challenging ethnocentric explanation of domestic violence. Let us decide and value our decision-a samoans response. Journal of Trauma, Violence and abuse. Vol.2 No.3

Ferguson, David.,Horwood, John., and Ridder, Elizabeth. 2005. Partner violence and mental health outcomes in new Zealand birth control. Journal of marriage and family 67

Itzhaky,H., and Porat,A.B.2005. Battered women in shelters: internal Resources, well-being and integration. AFFILIA Vol.20 (1),

Johnson, Michael P. 2005. Domestic violence its not about gender: or is it?. Journal of marriage and family. Vol. 67. No.5

Kalmuss,D.S.,and Strauss,M.A. 1982. Wife's marital dependency and wife abuse. Journal of marriage and the family. No.44

Lynch,S.M and Graham-Bermann,S.A. 2004. Exploring the relationship between positive work experiences and women's sense of self in the context of partner abuse. Psychology of women quarterly. No.28

Papadakaki,M.,Tzamalouka,G.S.,Chatzifotiou.,S.,and Chiloutakis,J. 2009. Seeking for risk factors of intimate partner violence in a greek national sample. Journal of interpersonal violence, Vol.24 (5) 
Sorensen. 2006. Breaking the chain of low self esteem. United state: Wolf publishing co

Stanley, Selwyn. 2012. Intimate partner violence and domestic myths: a comparison of women with and without alcoholic husbands (a study from India). Journal of comparative family studies. Vol. 43 No. 5

Sultana, Abeda.2010. Patriarchy and women's subordination: a Theoretical analysis. The Arts Faculty Journal.

Tracy, Steven. 2007. Partriarchy and domestic violence: challenging common misconceptions. Journal of evangelical theological society. Vol.50 No.3

Yount, Kathryn M and Carrera, Jennifer. 2006. Domestic Violence against married women in cambodja. Social force. Vol.85 No.1

World Health Organization. 2003. The WHO multicountry study on women's health and domestic violence against women.WHO violence against women instrument 